\title{
Breast cancer risk in elderly women with systemic autoimmune rheumatic diseases: a population-based case-control study
}

\author{
SM Gadalla',2, S Amr'², P Langenberg ${ }^{2}$, M Baumgarten², WF Davidson ${ }^{3}$, C Schairer', EA Engels', RM Pfeiffer' \\ and JJ Goedert ${ }^{*, I}$
}

'Division of Cancer Epidemiology and Genetics, National Cancer Institute, Bethesda, MD 20892, USA; ${ }^{2}$ Department of Epidemiology and Preventive Medicine, School of Medicine, University of Maryland, Baltimore, MD 2 I 20 I, USA; ${ }^{3}$ Department of Microbiology and Immunology, School of Medicine, University of Maryland, Baltimore, MD 2I 20 I, USA

\begin{abstract}
Systemic autoimmune rheumatic diseases (SARDs) are chronic inflammatory and immuno-modulatory conditions that have been suggested to affect cancer risk. Using the Surveillance, Epidemiology and End Results-Medicare-linked database, women aged 67-99 years and diagnosed with incident breast cancer in 1993-2002 ( $n=84778)$ were compared with an equal number of age-matched cancer-free female controls. Diagnoses of SARDs, including rheumatoid arthritis (RA, $n=5238$ ), systemic lupus erythematosus (SLE, $n=340)$, Sjogren's syndrome $(n=374)$, systemic sclerosis $(n=128)$, and dermatomyositis $(n=31)$, were determined from claim files for individuals from age 65 years to I year before selection. Associations of SARD diagnoses with breast cancer, overall and by oestrogen receptor (ER) expression, were assessed using odds ratio (OR) estimates from multivariable logistic regression models. The women diagnosed with RA were less likely to develop breast cancer $(\mathrm{OR}=0.87,95 \%$ confidence interval $(\mathrm{Cl})=0.82-0.93)$. The risk reduction did not differ by tumour ER-status $(\mathrm{OR}=0.83,95 \% \mathrm{Cl}=0.78-0.89$ for ER-positive vs $\mathrm{OR}=0.9 \mathrm{l}, 95 \% \mathrm{Cl}=0.8 \mathrm{I}-\mathrm{I} .04$ for ER-negative, $P$ for heterogeneity $=0.14$ ). The breast cancer risk was not associated with any of the other SARDs, except for a risk reduction of ER-negative cases $(\mathrm{OR}=0.49,95 \% \mathrm{Cl}=0.26-0.93)$ among women with $\mathrm{SLE}$. These findings suggest that systemic inflammation may affect breast epithelial neoplasia.
\end{abstract}

British Journal of Cancer (2009) 1 00, 817-821. doi:10.1038/sj.bjc.6604906 www.bjcancer.com

Published online 3 February 2009

(c) 2009 Cancer Research UK

Keywords: rheumatic diseases; autoimmune diseases; breast cancer

Breast cancer $(\mathrm{BC})$, the commonest malignancy and the second leading cause of cancer death among American women (American Cancer Society, 2007), is heterogeneous, particularly with respect to expressions of oestrogen and progesterone receptors. Oestrogen receptor (ER) status is of special interest because of its clinical implication (Andry et al, 1989; Hess et al, 2003). The fact that known BC risk factors account for only $45-55 \%$ of the cases (Willett et al, 2004) indicates the need for further research. Systemic autoimmune rheumatic diseases (SARDs) predominantly affect women (Cooper and Stroehla, 2003). They include rheumatoid arthritis (RA), systemic lupus erythematosus (SLE), Sjogren's syndrome, systemic sclerosis, and dermatomyositis (Marrow et al, 1999). Typically, these are associated with activation of autoreactive $\mathrm{T}$ and $\mathrm{B}$ lymphocytes and release of pro-inflammatory cytokines, which may alter cancer risk (Salazar-Onfray et al, 2007).

Several studies of SARDs and breast cancer risk have had inconsistent results (Hill et al, 2003; Chatterjee et al, 2005; Derk et al, 2006; Kontos and Fentiman, 2008; Smitten et al, 2008), which may reflect limitations such as small sample size, short time of follow-up, selection bias in hospital-based cohorts, detection bias, or reverse causality with a short interval between SARD diagnoses and BC. In addition, if any BC risk associated with SARDs is

*Correspondence: Dr JJ Goedert; E-mail: goedertj@mail.nih.gov Received I 8 November 2008; revised 9 January 2009; accepted 9 January 2009; published online 3 February 2009
ER-specific, the distribution of ER status in the studied populations might lead to conflicting results.

We conducted a population-based case-control study using the Surveillance, Epidemiology and End Results (SEER)-Medicarelinked database to evaluate whether a history of SARD diagnoses was associated with BC risk overall and by ER status of the tumour.

\section{SUBJECTS AND METHODS}

The SEER-Medicare data linkage, a collaboration of the National Cancer Institute and the Center for Medicare and Medicaid Services, was created by linking two large population-based data sources: the SEER cancer registry system and the Medicare enrolment and claim files. Detailed description of the database is available elsewhere (Warren et al, 2002). Briefly, it includes all incident cancer cases recorded by SEER registries, currently encompassing $\sim 25 \%$ of the US population, plus a $5 \%$ random sample of all Medicare beneficiaries residing in SEER areas to serve as population-based controls. The Medicare part of the linkage includes data from inpatient claims since 1986 and from all other types of claims (outpatient, physician, home health, and hospice services) since 1991. The database does not include claims for Medicare beneficiaries during enrolment in a health maintenance organisation (HMO). Clinical diagnoses are coded using the International Classification of Diseases, 9th Revision (ICD-9) codes (US Public Health Service, 1996). 
From the SEER database, we included all women with incident primary invasive adenocarcinoma of the breast (ICD-O-3 C500C509; histology codes 8140, 8201, 8211, 8480, 8500, 8501, 8503, $8504,8520,8521,8522,8523,8524,8530,8541$, and 8543; and behaviour code 3) who were diagnosed in 1993-2002, with no previous cancer of any type; $\mathrm{BC}$ cases diagnosed only at autopsy or by death certificate were excluded.

Female controls who were alive and cancer free as of 1 July of the calendar year of case selection were selected at random, with replacement, from the $5 \%$ sample of the Medicare beneficiaries who resided in SEER areas. To ensure availability of claims data, cases and controls had to be 67-99 years of age, selected in 1993 or later, and have at least 12 months of simultaneous part A and B coverage (and no HMO coverage) before the selection date. Controls were frequency matched in 1:1 ratio to cases according to the calendar year of diagnosis and age in three categories $(67-74,75-84$, and $85+)$. Women who became BC cases could be selected as controls until they were diagnosed with the cancer.

Participants were considered to have SARDs if they had at least one inpatient or two outpatient/physician claims (with a minimum interval of 30 days between claims) for any of the following diagnoses: RA (ICD-9 714.0, 714.1, 714.2, 714.3, 714.81, or V82.1), SLE (710.0), systemic sclerosis (710.1), Sjogren's syndrome (710.2), or dermatomyositis (710.3). Women who met the definition for more than one condition were included in a separate category, multiple SARDs. History of SARDs was ascertained from Medicare claim files, up to 12 months before case-control selection date.

Variables assessed as potential confounders of associations between BC and SARDs included age, race, socio-economic status, region of residence, history of mammography, number of physician visits 12-24 months before selection, and earlier use of immunosuppressive medications. We used the 1990 census median annual household income in the study participants' zip code of residence as a proxy measure of individuals' socioeconomic status. The regions of residence, based on the location of the SEER registry, were categorised as western, northeastern, north-central, and southern (Table 1). History of mammography was defined as any mammography claim recorded from 12 months to a maximum of 48 months before case - control selection. History of immunosuppressive therapy was defined as any Medicare claim for the following between age 65 years and 12 months before the case-control selection: cyclophosphamide, methotrexate, chlorambucil, azathioprine, cyclosporine, mycophenolate mofetil, sirolimus, tacrolimus, prednisone, prednisolone, methyl prednisolone, and immunosuppressive medication not otherwise specified.

\section{Statistical analysis}

We used unconditional logistic regression to calculate odds ratios (ORs) and 95\% confidence intervals (CIs) for the association between BC risk and SARDs (overall and for each condition). We computed the variance of the OR estimates using a robust variance estimator (Zeger and Liang, 1986) to adjust for the correlations between observations when the same participant was selected in different calendar years.

In evaluating BC risk by ER status, we excluded cases with unknown ER expression. We used polytomous logistic regression to estimate ORs and 95\% CIs with a robust variance estimator comparing ER-positive cases and ER-negative cases with the cancer-free controls (Anderson et al, 2008). A Wald test with one degree of freedom was used to test for the heterogeneity in the estimated regression coefficient for specific SARDs between ER-positive and ER-negative cases.

All final models were adjusted for age and year of selection (matching variables), race, region of residence, median-household income by zip code of residence, history of mammography, and history of immunosuppressive therapy as defined earlier. We also stratified all the models by year of selection in three groups
(1993-95, 1996-99, and 2000-02) to investigate whether the estimated associations were affected by secular trends in coding accuracy, mammography screening, or standard of care. In the final models that evaluated overall BC risk associated with SARDs (overall and by condition), we added two interaction terms, age $(\geqslant 75 v s<75)$ and race (whites $v s$ others), to test whether these associations are modified by age or race.

\section{RESULTS}

The study included 84778 BC cases and an equal number of cancer-free controls. Most of the cases (78.2\%) had known ER status, of whom $84.9 \%$ were ER-positive. As shown in Table 1, cases and controls had similar age distribution (median $=67$ years), region of residence, duration of Medicare coverage (median = 101 vs 102 months, respectively), and number of visits to physicians from 12 to 24 months before case-control selection ( median $=12$ vs 11 visits, respectively). However, more cases than controls were white $(88.4$ vs $83.7 \%)$, and had history of mammography 12-48 months before selection (50.5 vs 45.4\%). Patterns were similar for ER-positive and ER-negative cases, with the exception of race, for which more ER-negative cases than controls were black (9.4 vs 7.7\%) (Table 1).

Breast cancer cases with unknown ER status were similar to those with known status with respect to SARD distribution, but they were more likely to be diagnosed between 1993 and 1995 (26.5 vs $21.4 \%$ ), have tumours of unknown grade (25.3 vs $12.3 \%$ ), have non-specific morphology (10.8 vs $1.5 \%)$, and no recorded stage (5.6 vs $0.7 \%)$. Although statistically significant, absolute differences between cases with known and unknown ER status with respect to age, race, and income were small $(<5 \%)$ (Supplementary Table S1).

Of all participants, $4.0 \%(n=3033$ in BC cases and 3396 in the controls) met the study definition of at least one SARD condition. Among them, 95.2\% had only one condition. Of those who had been diagnosed with more than one condition, $84.6 \%$ had RA.

In unadjusted analyses, history of having any SARD diagnosis was inversely associated with breast cancer risk $(\mathrm{OR}=0.89,95 \%$ $\mathrm{CI}=0.84-0.93)$. When comparing individual SARD cases with no SARD cases, only RA was significantly associated with a decreased $\mathrm{BC}$ risk $(\mathrm{OR}=0.87,95 \% \mathrm{CI}=0.82-0.92)$ (data not shown). Multivariable regression models showed similar results (Table 2). Similar results were also obtained when we stratified the models by year of selection (data not shown). No significant interactions were found with age or race in the association between BC and SARD (overall or for individual condition, data not presented).

When comparing ER-positive and ER-negative cases with cancer-free controls in unadjusted analysis, RA was inversely associated with both ER-positive and ER-negative BC risk $(\mathrm{OR}=0.83,95 \% \mathrm{CI}=0.78-0.89$, and $\mathrm{OR}=0.90,95 \% \mathrm{CI}=0.80-$ 1.03 , respectively), whereas SLE was inversely associated only with ER-negative tumours $(\mathrm{OR}=0.50,95 \% \mathrm{CI}=0.27-0.95)$ (data not shown). Multivariable analysis showed similar results (Table 2). Heterogeneity in the estimated ORs of ER-positive and ERnegative $\mathrm{BC}$ associated with SARDs was only significant in the case of SLE $(\mathrm{OR}=1.08,95 \% \mathrm{CI}=0.85-1.40$, and $\mathrm{OR}=0.49,95 \%$ $\mathrm{CI}=0.26-0.94$, respectively, $P=0.02$ ). Results obtained from stratified models by year of case - control selection and unstratified models were similar, except for an attenuation of the risk deficit for ER-positive BC with RA in recent years $(\mathrm{OR}=0.76,0.83$, and 0.85 for $1993-1995,1996-1999$, and $2000-2002$, respectively, $P$ for trend $<0.0001$ ) (Supplementary Table S2).

\section{DISCUSSION}

Our study found a reduced BC risk associated with RA that did not differ by the ER-status of the tumour. We also observed a reduced 
Table I Characteristics of breast cancer cases (overall and by ER status) and controls

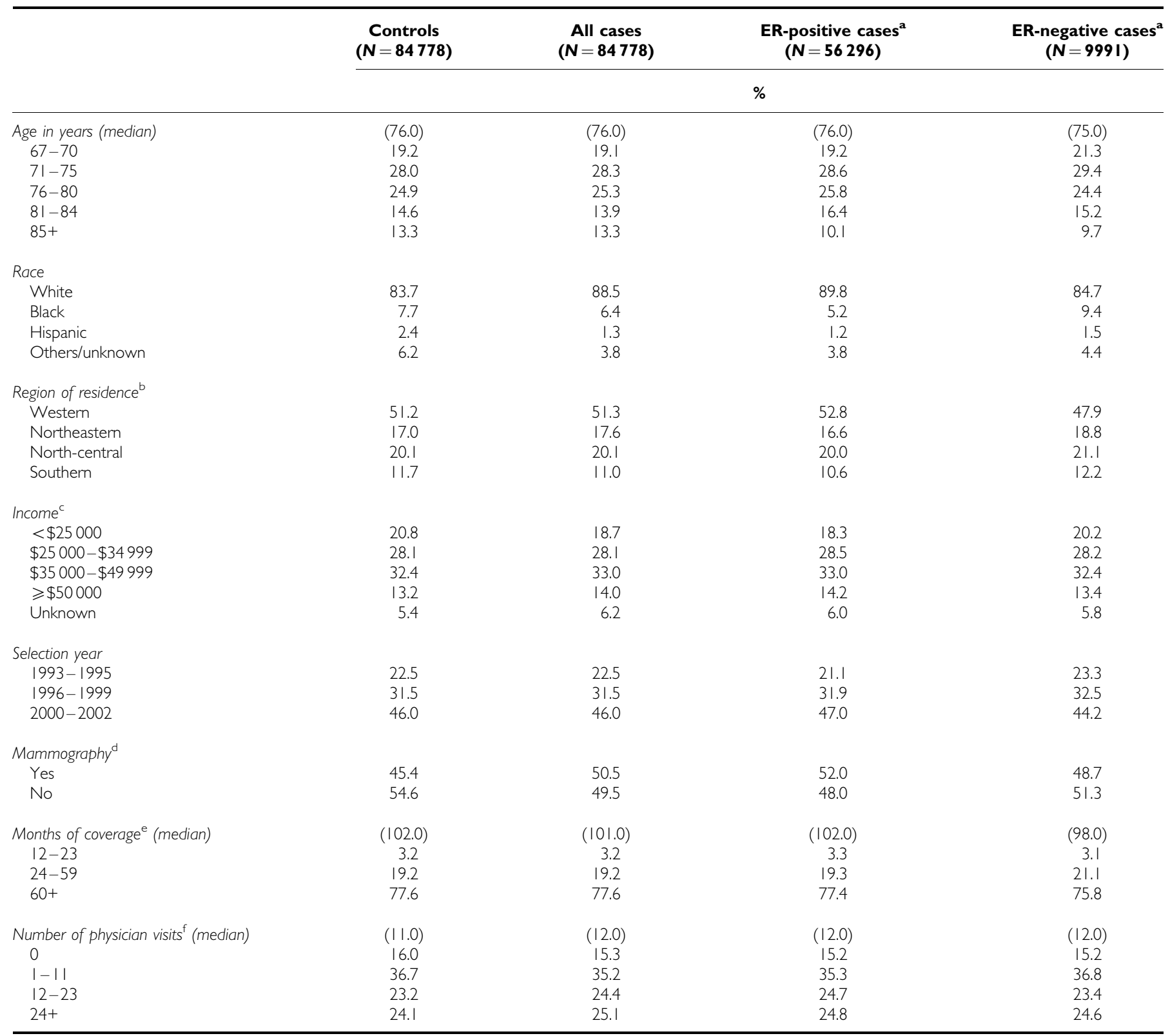

${ }^{a}$ ER status is missing for 18491 breast cancer cases ${ }^{b}$ Western region includes Hawaii, New Mexico, San Francisco, Seattle, Utah, San Jose, Los Angeles, and Greater California; North eastern region includes Connecticut and New Jersey; North-central includes Detroit and lowa; Southern region includes Atlanta, rural Georgia, Kentucky, and Louisiana. Median household income by residential zip code. ${ }^{\mathrm{d}}$ Ever had mammography $12-48$ months before case-control selection. ${ }^{\mathrm{N}} \mathrm{Number}$ of months of total simultaneous coverage part A, B, and non-HMO. ${ }^{\mathrm{N}}$ Number of visits to a physician $12-24$ months before case-control selection.

risk in women with SLE that was confined to ER-negative tumours. None of the other SARDs investigated was associated with BC risk overall or by ER status.

Our observed association for RA agrees with the results of a recent meta-analysis that reported a pooled standardised incidence ratio of $0.84(95 \% \mathrm{CI}=0.79-0.90)$ for breast cancer among women with RA (Smitten et al, 2008). For SLE, our results are consistent with the overall null associations reported by studies that recruited a wide spectrum of SLE patients (Cibere et al, 2001; Ragnarsson et al, 2003), but they contrast with the protective effect observed in studies that recruited the SLE patients from inpatient records or tertiary care units, which are likely to over-represent severe SLE cases (Bjornadal et al, 2002; Bernatsky et al, 2005). Perhaps disease activity, severity, or treatment affects its relationship to BC risk.
No earlier study evaluated this association by the tumour ER-specific subtypes.

The variation in BC risk with different SARD conditions might reflect differences in cytokine profiles. For example, high circulating levels of tumour necrosis factor-alpha (TNF- $\alpha$ ) and transforming growth factor-beta (TGF- $\beta$ ) have been reported in patients with RA (Arend and Gabay, 2004), but not in patients with Sjogren's syndrome (Garcic-Carrasco et al, 2001; Eriksson et al, 2004). Both TNF- $\alpha$ and TGF- $\beta$ have been reported to suppress breast cancer cell proliferation, predominantly against ER-positive cells (Sgagias et al, 1991; Grimm and Rosen, 2006). On the other hand, SLE patients (Lub-de Hooge et al, 2005; Rus et al, 2005), and to a lesser extent RA patients (Xie et al, 2007), have elevated serum levels of TNF-related apoptosis-inducing ligand (TRAIL). TRAIL has been shown to 
Table 2 Adjusted association between breast cancer (overall and by ER status) and SARD conditions

\begin{tabular}{|c|c|c|c|c|c|c|}
\hline \multirow[b]{2}{*}{ SARD } & \multicolumn{2}{|c|}{$\begin{array}{l}\text { All cases-control } \\
(N=84778)\end{array}$} & \multicolumn{2}{|c|}{$\begin{array}{c}\text { ER-positive } \\
\text { cases-control }(N=56296)\end{array}$} & \multicolumn{2}{|c|}{$\begin{array}{c}\text { ER-negative } \\
\text { cases-control }(N=9991)\end{array}$} \\
\hline & $\mathbf{N}$ & OR $(95 \% C I)^{a}$ & $N$ & OR $(95 \% C I)^{a}$ & $N$ & OR $(95 \% \mathrm{CI})^{\mathrm{a}}$ \\
\hline \multicolumn{7}{|l|}{ By condition } \\
\hline
\end{tabular}

${ }^{a}$ Odds ratios (ORs) and $95 \%$ confidence intervals (Cls) are adjusted for age, year of selection, race, mammography, region of residence, income, and immunosuppressive therapy ${ }^{\mathrm{b}} \mathrm{P}<0.05$.

induce apoptosis in ER-negative, but not in ER-positive cell lines (Rahman et al, 2009), perhaps explaining our observed reduced risk of ER-negative, but not of ER-positive, breast cancer in women with SLE. Although plausible, we were not able to rule out the possibility that the observed inverse association with RA might be confounded by the use of nonsteroidal anti-inflammatory drugs (NSAIDs). The NSAIDs seem to have a protective effect against BC (Coogan et al, 1999; Johnson et al, 2002; Harris et al, 2003; Takkouche et al, 2008). However, the generally null associations with SARD conditions, with the notable exception of RA, suggest that use of NSAIDs does not explain the observed associations.

Possible differences in known BC risk factors that were not available in our study, such as parity, age at first birth, obesity, alcohol consumption, and use of hormone therapy, should also be considered. It seems unlikely that they completely explain the observed associations, as these are the risk factors for ER-positive, but not for ER-negative tumours (Chen and Colditz, 2007). In addition, the low body mass index (BMI) prevalent in women with RA is mainly because of muscle wasting rather than low body fat (Munro and Capell, 1997), and thus is less likely to affect levels of endogenous oestrogens, which are thought to mediate the association between BMI and BC. Also, these factors did not completely confound the association between SLE and BC in an earlier study (Bernatsky et al, 2003).

Our study strengths include population-based sampling of the participants and a large sample size. The SEER-Medicare-linked database allowed the identification of incident breast cancer cases and provided detailed tumour information. In addition, we captured SARD conditions from inpatient, outpatient, and physician claims, minimising selection bias by capturing the whole spectrum of the diseases, including the one-quarter of SARD patients who were treated only as outpatients. Exclusion of the 1 year before casecontrol selection minimised the possibility of reverse causality and detection bias that could result from increased medical surveillance around the time of cancer diagnosis.

\section{REFERENCES}

American Cancer Society (2007) Cancer Facts \& Figures 2007. American Cancer Society: Atlanta

Anderson LA, Pfeiffer R, Warren JL, Landgren O, Gadalla S, Berndt SI, Ricker W, Parsons R, Wheeler W, Engels EA (2008) Hematopoietic malignancies associated with viral and alcoholic hepatitis. Cancer Epidemiol Biomarkers Prev 17: 3069-3075

Andry G, Suciu S, Pratola D, Sylvester R, Leclercq G, da Costa PM, Legros N, Andry-t'Hooft M, Verhest A, Mattheiem W (1989)
Study limitations include the lack of information on important $\mathrm{BC}$ risk factors such as obesity and parity, as well as detailed medical information about the SARD conditions, including severity, duration, and detailed treatment history. We adjusted for the use of immunosuppressive medications; however, underestimation of the actual use is expected, especially for the less expensive oral medications, such as corticosteroids, because of the medication coverage rules of Medicare. The missing information on ER expression for one-fifth of the BC cases might be a source of bias. However, the equal distribution of SARD conditions in BC cases with known and unknown ER status suggests that substantial differential bias is unlikely.

In conclusion, this study provides evidence for a reduced risk of $\mathrm{BC}$ in older women with RA and also suggests that older women with SLE may be at reduced risk for ER-negative BC, suggesting a possible role for systemic mediators of inflammation and immunity against BC cells.

\section{ACKNOWLEDGEMENTS}

This research was supported by an intramural fellowship at the National Cancer Institute. We acknowledge the efforts of Dr Joan Warren, Applied Research Programme, Division of Cancer Control and Population Sciences, NCI, in facilitating our access and understanding of the different components of the SEER-Medicare database, and Ms Winnie Ricker and Ms Ruth Parsons, Information Management Services Inc. (IMS), in managing the project dataset. Dr Gadalla is currently supported by the Cancer Prevention Fellowship Program, National Cancer Institute.

Supplementary Information accompanies the paper on British Journal of Cancer website (http://www.nature.com/bjc)
Relation between estrogen receptor concentration and clinical and histological factors: their relative prognostic importance after radical mastectomy for primary breast cancer. Eur J Cancer Clin Oncol 25: $319-329$

Arend WP, Gabay C (2004) Cytokines in the rheumatic diseases. Rheum Dis Clin North Am 30: 41-vi

Bernatsky S, Boivin JF, Joseph L, Rajan R, Zoma A, Manzi S, Ginzler E, Urowitz M, Gladman D, Fortin PR, Petri M, Edworthy S, Barr S, Gordon 
C, Bae SC, Sibley J, Isenberg D, Rahman A, Aranow C, Dooley MA, Steinsson K, Nived O, Sturfelt G, Alarcon G, Senecal JL, Zummer M, Hanly J, Ensworth S, Pope J, El Gabalawy H, McCarthy T, St Pierre Y, Ramsey-Goldman R, Clarke A (2005) An international cohort study of cancer in systemic lupus erythematosus. Arthritis Rheum 52: $1481-1490$

Bernatsky S, Ramsey-Goldman R, Boivin JF, Joseph L, Moore AD, Rajan R, Clarke A (2003) Do traditional Gail model risk factors account for increased breast cancer in women with lupus? J Rheumatol 30: $1505-1507$

Bjornadal L, Lofstrom B, Yin L, Lundberg IE, Ekbom A (2002) Increased cancer incidence in a Swedish cohort of patients with systemic lupus erythematosus. Scand J Rheumatol 31: 66-71

Chatterjee S, Dombi GW, Severson RK, Mayes MD (2005) Risk of malignancy in scleroderma: a population-based cohort study. Arthritis Rheum 52: 2415-2424

Chen WY, Colditz GA (2007) Risk factors and hormone-receptor status: epidemiology, risk-prediction models and treatment implications for breast cancer. Nat Clin Pract Oncol 4: 415-423

Cibere J, Sibley J, Haga M (2001) Systemic lupus erythematosus and the risk of malignancy. Lupus 10: 394-400

Coogan PF, Rao SR, Rosenberg L, Palmer JR, Strom BL, Zauber AG, Stolley PD, Shapiro S (1999) The relationship of nonsteroidal anti-inflammatory drug use to the risk of breast cancer. Prev Med 29: $72-76$

Cooper GS, Stroehla BC (2003) The epidemiology of autoimmune diseases. Autoimmun Rev 2: 119-125

Derk CT, Rasheed M, Artlett CM, Jimenez SA (2006) A cohort study of cancer incidence in systemic sclerosis. J Rheumatol 33: 1113-1116

Eriksson P, Andersson C, Ekerfelt C, Ernerudh J, Skogh T (2004) Relationship between serum levels of IL-18 and IgG1 in patients with primary Sjogren's syndrome, rheumatoid arthritis and healthy controls. Clin Exp Immunol 137: 617-620

Garcic-Carrasco M, Font J, Filella X, Cervera R, Ramos-Casals M, Siso A, Aymami A, Ballesta AM, Ingelmo M (2001) Circulating levels of Th1/Th2 cytokines in patients with primary Sjogren's syndrome: correlation with clinical and immunological features. Clin Exp Rheumatol 19: $411-415$

Grimm SL, Rosen JM (2006) Stop! In the name of transforming growth factor-beta: keeping estrogen receptor-alpha-positive mammary epithelial cells from proliferating. Breast Cancer Res 8: 106

Harris RE, Chlebowski RT, Jackson RD, Frid DJ, Ascenseo JL, Anderson G, Loar A, Rodabough RJ, White E, McTiernan A (2003) Breast cancer and nonsteroidal anti-inflammatory drugs: prospective results from the Women's Health Initiative. Cancer Res 63: 6096-6101

Hess KR, Pusztai L, Buzdar AU, Hortobagyi GN (2003) Estrogen receptors and distinct patterns of breast cancer relapse. Breast Cancer Res Treat 78: $105-118$

Hill CL, Nguyen AM, Roder D, Roberts-Thomson P (2003) Risk of cancer in patients with scleroderma: a population based cohort study. Ann Rheum Dis 62: $728-731$
Johnson TW, Anderson KE, Lazovich D, Folsom AR (2002) Association of aspirin and nonsteroidal anti-inflammatory drug use with breast cancer. Cancer Epidemiol Biomarkers Prev 11: 1586-1591

Kontos M, Fentiman IS (2008) Systemic lupus erythematosus and breast cancer. Breast J 14: $81-86$

Lub-de Hooge MN, de Vries EG, de JS, Bijl M (2005) Soluble TRAIL concentrations are raised in patients with systemic lupus erythematosus. Ann Rheum Dis 64: 854-858

Marrow J, Nelson L, Watts R, Isenberg D (1999) Autoimmune Rheumatic Disease. Oxford University Press: Oxford

Munro R, Capell H (1997) Prevalence of low body mass in rheumatoid arthritis: association with the acute phase response. Ann Rheum Dis 56: $326-329$

Ragnarsson O, Grondal G, Steinsson K (2003) Risk of malignancy in an unselected cohort of Icelandic patients with systemic lupus erythematosus. Lupus 12: $687-691$

Rahman M, Davis SR, Pumphrey JG, Bao J, Nau MM, Meltzer PS, Lipkowitz $S$ (2009) TRAIL induces apoptosis in triple-negative breast cancer cells with a mesenchymal phenotype. Breast Cancer Res Treat 113(2): 217-230

Rus V, Zernetkina V, Puliaev R, Cudrici C, Mathai S, Via CS (2005) Increased expression and release of functional tumor necrosis factorrelated apoptosis-inducing ligand (TRAIL) by $\mathrm{T}$ cells from lupus patients with active disease. Clin Immunol 117: 48-56

Salazar-Onfray F, Lopez MN, Mendoza-Naranjo A (2007) Paradoxical effects of cytokines in tumor immune surveillance and tumor immune escape. Cytokine Growth Factor Rev 18: $171-182$

Sgagias MK, Kasid A, Danforth Jr DN (1991) Interleukin-1 alpha and tumor necrosis factor-alpha (TNF alpha) inhibit growth and induce TNF messenger RNA in MCF-7 human breast cancer cells. Mol Endocrinol 5: $1740-1747$

Smitten AL, Simon TA, Hochberg MC, Suissa S (2008) A meta-analysis of the incidence of malignancy in adult patients with rheumatoid arthritis. Arthritis Res Ther 10: R45

Takkouche B, Regueira-Mendez C, Etminan M (2008) Breast cancer and use of nonsteroidal anti-inflammatory drugs: a meta-analysis. J Natl Cancer Inst 100: $1439-1447$

US Public Health Service (1996) International Classification of Diseases, 9th revision. 92-1260 US GPO; (PHS): Washington, DC

Warren JL, Klabunde CN, Schrag D, Bach PB, Riley GF (2002) Overview of the SEER-Medicare data: content, research applications, and generalizability to the United States elderly population. Med Care 40: IV-18

Willett WC, Rockhill B, Hankinson S, Hunter D, Colditz G (2004) Nongentic factors in the causation of breast cancer. In Diseases of the Breast, Jay Harris (ed), pp 223-277. Lippincott Williams \& Wilkins: Philadelphia, PA, USA

Xie YD, Jin L, Yu QW (2007) The role of IFN-gamma IL-10 IL-12 TRAIL in sera, synovial fluids from patients with rheumatoid arthritis. Xi Bao Yu Fen Zi Mian Yi Xue Za Zhi 23(6): 536-537 (Abstract)

Zeger SL, Liang KY (1986) Longitudinal data analysis for discrete and continuous outcomes. Biometrics 42: 121-130 